\title{
A New Approach of Almost Periodic Lumped Elements Circuits by an Iterative Method Using Auxiliary Sources
}

\author{
${ }^{1}$ Mohamed Karim Azizi, ${ }^{1}$ Lassaad Latrach, \\ ${ }^{2}$ Nathalie Raveu, ${ }^{1}$ Ali Gharsallah and ${ }^{2}$ Henri Baudrand \\ ${ }^{1}$ Unit of Research Circuits and Electronics Systems High Frequency, \\ Faculty of Science, University El Manar, Tunis, Tunisia \\ ${ }^{2}$ Laplace Lab, Department of Electronics, Faculty ENSEEIHT, University of Toulouse, France
}

Received 2013-04-29, Revised 2013-07-10; Accepted 2013-10-05

\begin{abstract}
Nowadays, met materials with lumped or distributed elements are emerging and it is necessary to develop new techniques based on the following principles. The approach should be global and have to be formulated according to the existing classic formulations. In fact, the Wave Concept Iterative Process (WCIP) is systematically used in such application. On the other hand, the periodic medium can have some cells with localized defects that are supposed to be almost periodic. Such structures are studied based on the introduction of auxiliaries' sources. The study is devoted to the study of one dimensional then bi dimensional medium. Simple diffraction phenomenon supports the usefulness of the proposed new approach.
\end{abstract}

Keywords: WCIP, Almost Periodic, Auxiliary Sources

\section{INTRODUCTION}

In the last decades, many numerical methods have been developed and evolved to solve problems and model complex structures. The iterative method based on the Wave Concept (WCIP) is one of the most effective in terms of accuracy and speed (Latrach et al., 2009).

The principle of the WCIP is based on two linked equations, one is in the spatial domain and the other in the spectral domain. The transition between the two areas being through an FFT enables computation time reduction.

In fact, this method has solved the problems associated with microwave and multilayer structures as shown in (Azizi et al., 2008).

Moro ever, several studies have been made by the iterative method such as planar antennas (Harizi and Gharsallah, 2012). The method has been proven to be efficient in modeling structures of circular antennas (Wang et al., 2008; Houaneb et al., 2011).
The WCIP has also shown its effectiveness in the study of frequency selective surfaces (Latrach et al., 2008; Aroussi et al., 2011; Li et al., 2006).

Originally, the WCIP was applied in structures where the pixels are homogeneous, such metal or dielectric application and planar circuits. The new approach presented in this study deals with cases where the pixels are themselves complex circuits. They are called "cells" that are arranged almost periodically, which means cells that are periodic but they have each one power supplies that are arbitrary. These sources can be replaced by impedances.

This change, in each cell, results in a breach of any rigorous periodicity. Hence the almost periodic nature because the break is made in a very small cell size front.

This new concept has allowed the Study of Integrated Circuits on a substrate (SIC) (Baudrand et al., 2009). These structures the auxiliary sources are via centered in cells. In the spectral domain, the reflection coefficient $\Gamma$ is calculated by the Helmholtz equation.

Corresponding Author: Mohamed Karim Azizi, Unit of Research Circuits and Electronics Systems High Frequency, Faculty of Science, University El Manar, Tunis, Tunisia 
Other studies on electromagnetic band gap structures (Azizi et al., 2011) have recently been initiated. Metamaterials with negative index behavior are the subject of several applications such as antennas (Eleftheriades and Balmain, 2005).

The first part of the article is devoted to a brief presentation of the iterative WCIP with the transition from one domain to another. Then the one-dimensional almost periodic circuits will be treated in the simple case of an artificial line. Third part will address the twodimensional almost periodic circuits.

In these studies the elements of each cell will be located; they describe the physical behavior of each cell. We will discuss the behavior of the field $E_{z}$ in an Iris structure and on a metal band.

Recently, new approaches and applications are open at almost periodic circuits such as filters, resonators power amplifiers.

\section{PRINCIPLES OF THE WCIP METHOD}

The wave concept is introduced by expressing the incident waves A and B reflected at the interface based on dual electromagnetic quantities as will be shown below. This method establishes a recurrence relation between the incident and reflected waves around discontinuities. It uses the Fast Modal transform.

To do this, the definition of waves must obey certain conditions such as the domain partition in two parts:

- The wave equation, treated fully and thus resulted in a relationship with the limits on a domain D

- The boundary conditions on the domain D
It is necessary to define a couple of variables connected in the dual and limitations of linear operators in a proportional relationship (internal D: lumped elements) and an integral relationship (external D): Current-voltage electric field, magnetic current density (volume or surface)-electric field. In the case of using via metal for example (Fig. 1) we define $\mathrm{E}$ and $\mathrm{J}$ variables as dual to study these Structures (SIC) with J being the mass density of the current and E being the electric field density.

In the case of the lumped constants, $\mathrm{E}$ and $\mathrm{J}$ are dual quantities. The use of auxiliary sources allows for $\mathrm{V}$ and $\mathrm{I}$ as dual variables that are defined at the source. The amplitude of the waves $\mathrm{A}$ and $\mathrm{B}$ are defined as follows Equation (1 and 2):

$$
\left\{\mathrm{A}=\frac{1}{2 \sqrt{\mathrm{Z}_{0}}}\left(\mathrm{E}+\mathrm{Z}_{0} \mathrm{~J}\right)\right.
$$

$$
\left\{\mathrm{B}=\frac{1}{2 \sqrt{\mathrm{Z}_{0}}}\left(\mathrm{E}-\mathrm{Z}_{0} \mathrm{~J}\right)\right.
$$

These variables also describe the behavior of auxiliary sources (Baudrand and Wane, 2009). The iterative process decomposes the problem into two stages.

Consider an electromagnetic environment with an element (or several) whose behavior is described in the system V-I, E-J or E-Js. As shown in (Fig. 2) we replace this element with a source (step 1) that the closure will be made by this element (step 2).

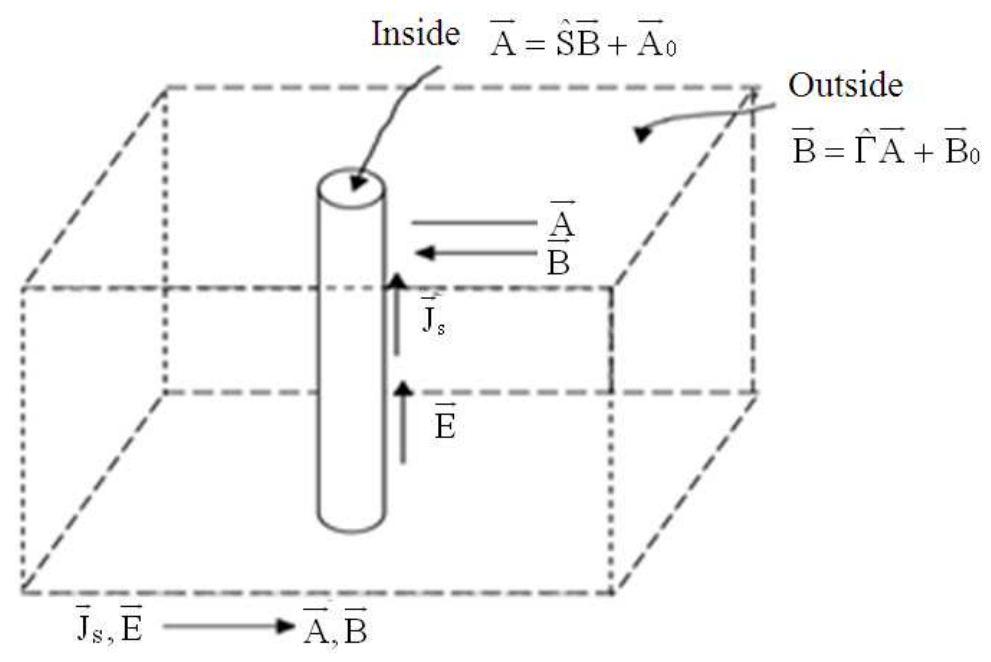

Fig. 1. Substrates Integrated Circuits (SIC) 

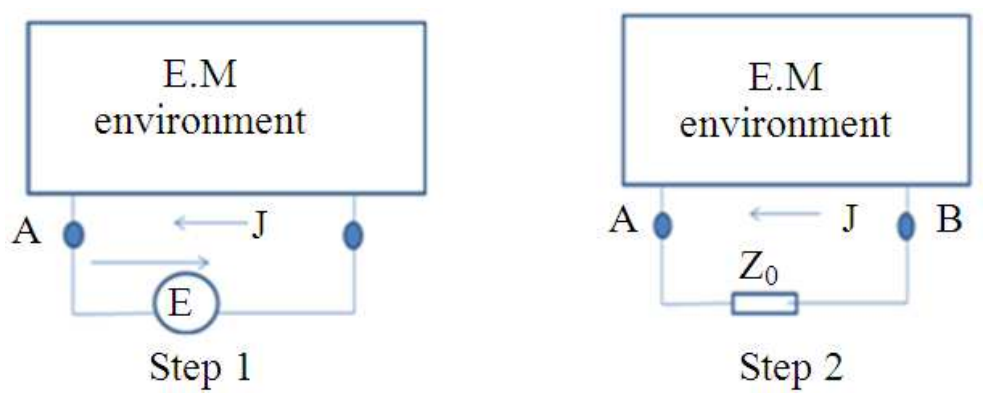

Fig. 2. The auxiliary source use

In step (1) the impedance (or source) of the initial circuit is replaced by a source.

The calculation gives the impedance (and potential source) of the source of the electromagnetic environment. This will be the operation in the spectral domain.

The step (2) consists in writing the source of step (1) (arbitrary source) as closed on the first circuit impedance.

These operations can be represented by the general scheme given in (Fig. 3). $\mathrm{S}_{0}$ is the main source which exists in the original problem (consisting in calculation of the impedance seen from So). $S_{1}$ is a localized source with internal impedance $Z_{0}$. $S$ is the auxiliary source.

The iterative process decomposes the problem into two parts, one in the space domain and the other in the frequency domain.

The periodicity of the structure allows define the spectral domain, the periodicity conditions imply a phase shift of $\alpha$ and $\beta$ in both directions between neighboring cells.

The elementary cell is characterized by $\mathrm{d}$ as the cell longer and $\mathrm{D}$ as the structure longer.

In case $D^{*} \mathrm{D}$ and knowing that the cell has a dimension of $\mathrm{d}^{*} \mathrm{~d}$ :

$$
\alpha(\mathrm{m})=2 \pi \mathrm{m} \frac{\mathrm{d}}{\mathrm{D}} \beta(\mathrm{n})=2 \pi \mathrm{n} \frac{\mathrm{d}}{\mathrm{D}}
$$

The whole set of these phase shifts the spectral domain, which is characterized by the operator $\Gamma$ (Baudrand and N'gongo, 1999) Equation (3):

$$
\hat{\Gamma}=\frac{Z_{\alpha}-Z_{0}}{Z_{\alpha}+Z_{0}}
$$

With $Z_{\alpha}$ is the impedance of mode at $\alpha$ stand:
$\overrightarrow{\mathrm{B}}=\hat{\Gamma} \overrightarrow{\mathrm{A}}$ spectral domain

$\overrightarrow{\mathrm{A}}=\mathrm{SB}+\overrightarrow{\mathrm{A}}_{0}$ spatial domain

The operator $\Gamma$ characterizes the propagation conditions; it is defined in the spectral domain.

The operator $\mathrm{S}$ characterizes the boundary conditions, it is defined in the spatial domain.

The transition of the spatial domain to the spectral domain is provided by the Fourier transform and its inverse. The iterative process described in (Fig. 4) apply the two Equation (4) and (5) until convergence. Thereafter we calculate the distribution of the current or field.

\section{ONE DIMENSIONAL ALMOST PERIODIC STRUCTURE}

Almost periodic one-dimensional circuits will be studied, these circuits are periodic except for sources. In a cells periodic structure (Fig. 5), each defect in a cell can be represented by replacing its source by impedances. Thus, structure became almost periodic.

This approach is well suited to the iterative method which acts as a balance between Spectral areas (outside) and Space (inside or sources).

It describes the periodic geometry (outside) with small spatial irregularities (area sources).

The transmission line is composed of $\mathrm{N}$ cells, each cell is surrounded by periodic walls and the passage from one cell to the other is done through a phase shift:

$$
\alpha=2 \pi \mathrm{m} \frac{\mathrm{d}}{\mathrm{D}}
$$

where, $d$ is the length of the cell and D is the length of the whole structure. 


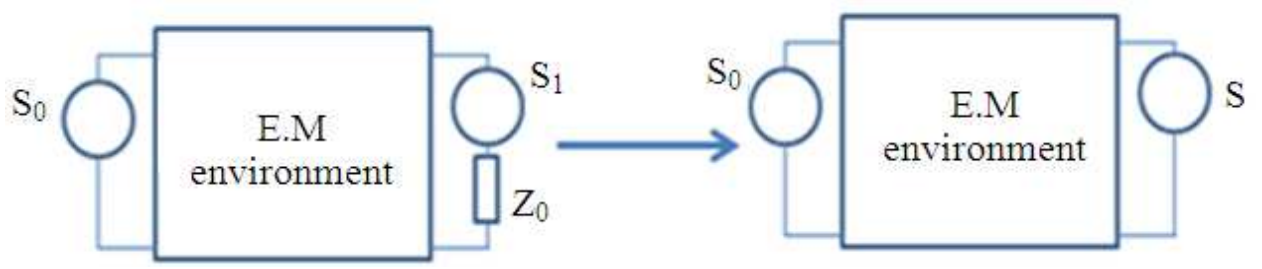

Fig. 3. Twoports description problem with an auxiliary source

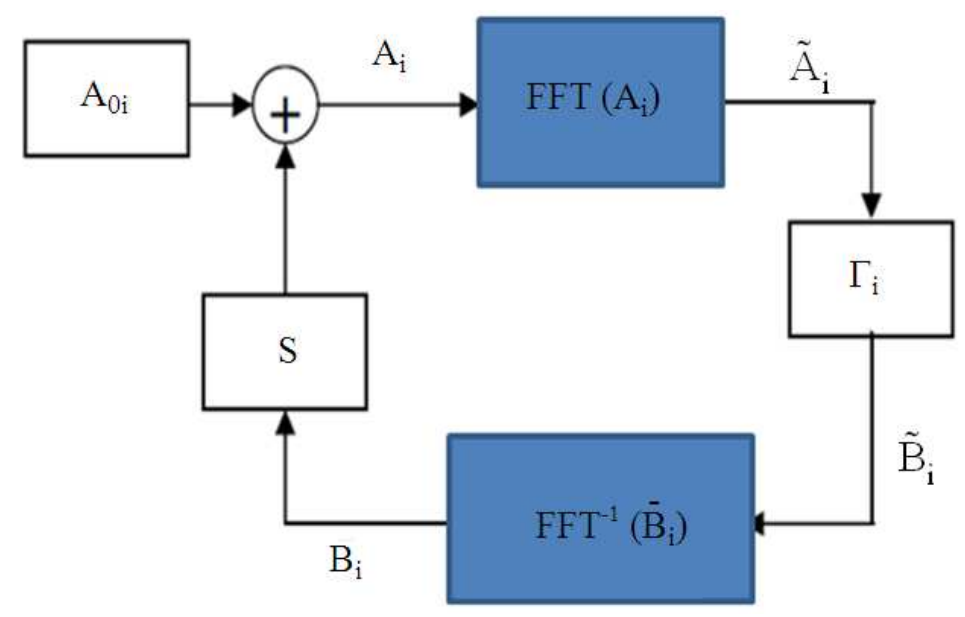

Fig. 4. Iterative processing principle

Auxiliary sources

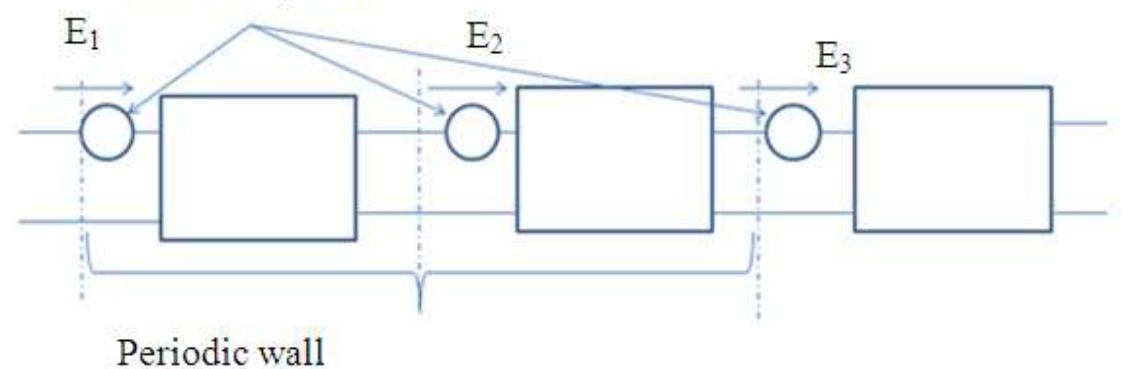

Fig. 5. One dimensional structure

The transmission line is as follows (Fig. 6) consists of 100 cells, each cell is surrounded by periodic walls, an electric wall is inserted at the last cell to create the overlap of the structure.

The problem with these circuits requires only a representation of I and $\mathrm{V}$.

The calculation of the current distribution allows to see the behavior of each cell.

The insertion of the electric wall at a distance D allows to antisymmetrize the structure (Fig. 7). This helps us to calculate electromagnetic at the half of the structure thus timeliness of calculation and allows to find the wavelength $\lambda$.

The choice of the structure: symmetrical position of the sources leads to skew the value of these sources.

The use of the antisymmetry plan can duplicate the structure and causes a variation in sinus instead of an exponential.

The antisymmetry of sources leads to the presence of electrical walls at the beginning and the middle of the structure. As a result, the main sources rely on an electric wall ensuring the closure of current lines. 
Mohamed Karim Azizi et al. / American Journal of Applied Sciences 10 (11): 1457-1472, 2013

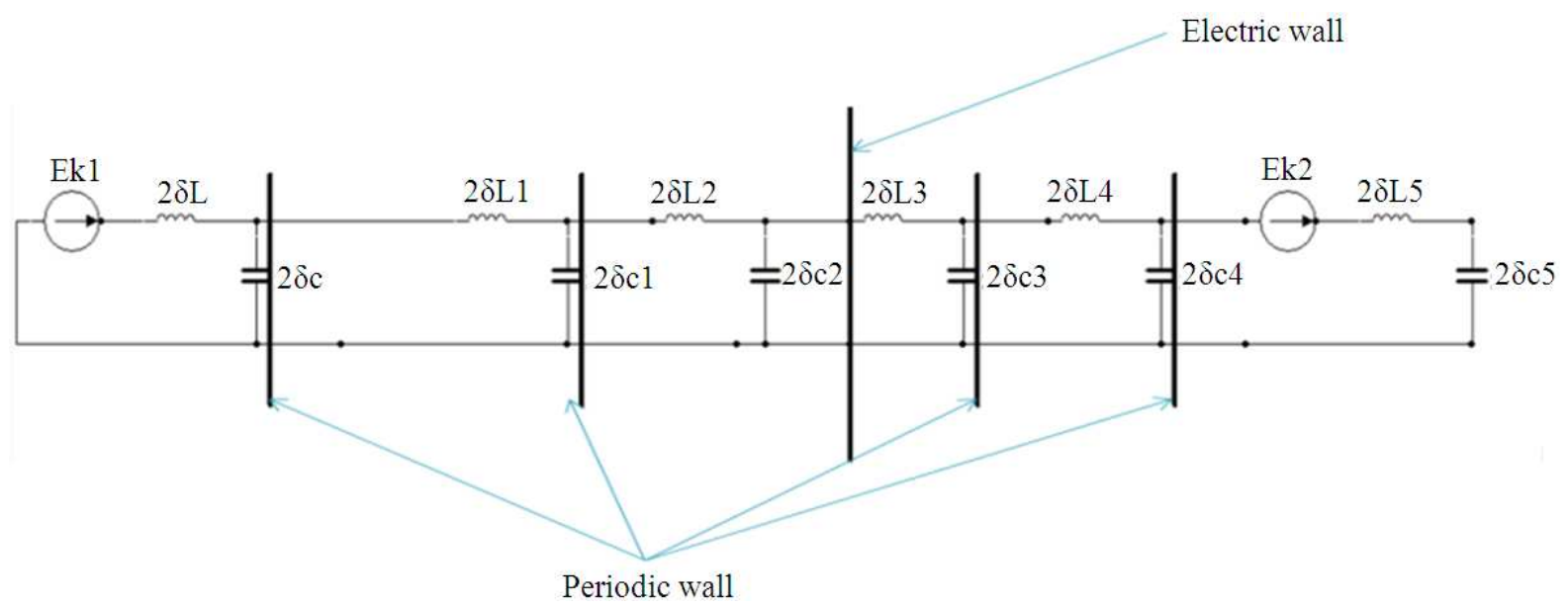

Fig. 6. A transmission line

Sources

antisymetriques

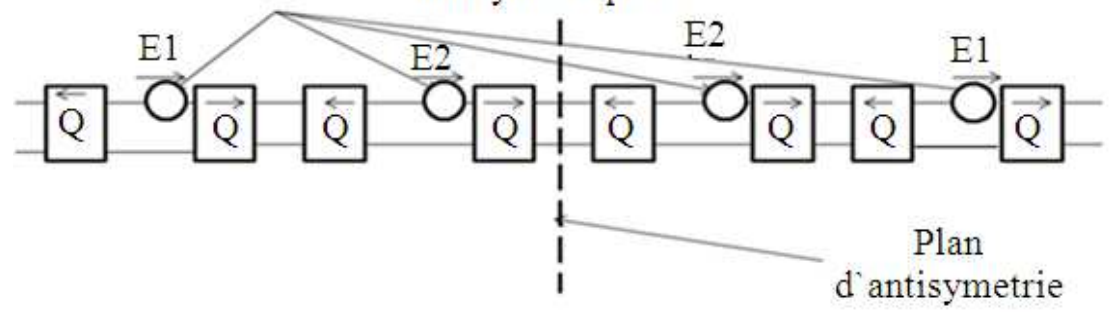

Fig. 7. Doubling of the structure

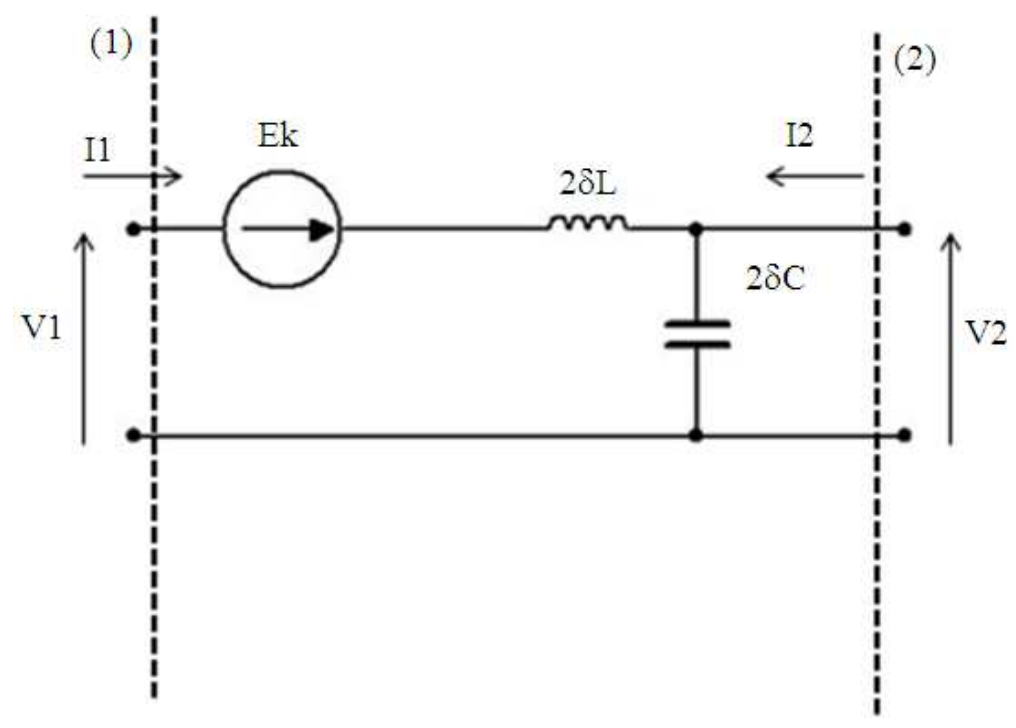

Fig. 8. Elementary single cell 


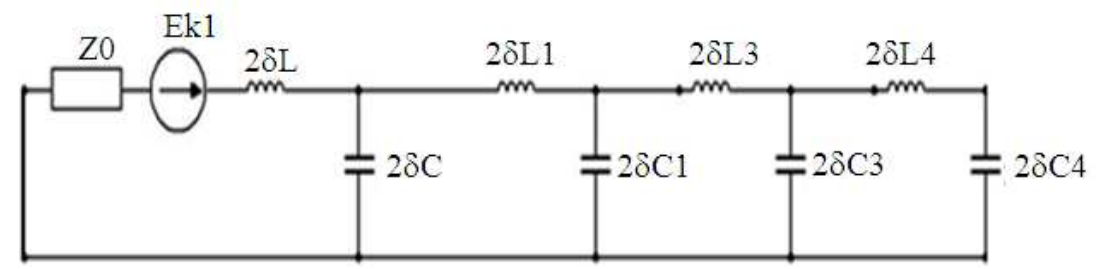

Fig. 9. Transmission line

The study of the whole structure comes down to the study of a single cell (Fig. 8) because it is surrounded by periodic walls.

In the state $\alpha$, the impedance $Z \alpha$ must be calculated, taking the unit cell of (Fig. 9), the law of the mesh used to write the following system.

Three relationships are:

$$
\begin{aligned}
& \mathrm{V}_{1}+\mathrm{j} 1 \omega \mathrm{I}_{1}+\mathrm{Ee}+\mathrm{j} 1 \omega \mathrm{I}_{1}=\mathrm{V}_{2} \\
& \mathrm{I}_{2}=-\mathrm{I}_{1} \mathrm{e}^{\mathrm{j} \alpha} \\
& \mathrm{I}_{1} \mathrm{e}^{\mathrm{j} \alpha}+\mathrm{I}_{1}+\mathrm{j} \omega \mathrm{c} \mathrm{V}_{1} \mathrm{e}^{\mathrm{j} \alpha}=0
\end{aligned}
$$

The transition from one cell to another is done through a phase shift $\alpha$, each cell is bounded by walls periodicals, periodic boundary conditions involve a phase shift difference between (1) and (2) were as follows:

$$
\mathrm{V}_{2}=\mathrm{V}_{1} \mathrm{e}^{\mathrm{j} \alpha}
$$

by replacing the Equation 9 in Equation 6, 10:

$$
V_{1}+j 1 \omega I_{1}+E e+j 1 \omega I_{1}=V_{1} e^{j \alpha}
$$

Law of nodes give Equation (11):

$I_{1}-j \omega c V_{2}=-I_{2}$

The last two Equation 7 and 8 give the system Equation (12 to 14$)$ :

$$
\begin{aligned}
& \left(j \omega c V_{1}-I_{1}\right) e^{j \alpha}+I_{1}+j \omega c V_{1} e^{j \alpha}=0 \\
& V_{1}=\frac{e^{j \alpha}-1}{2 j \omega c e^{j \alpha}} I_{1}
\end{aligned}
$$

By replacing in Equation 6:

$$
E=-2 j 1 \omega I_{1}+\frac{\left(e^{j \alpha}-1\right)^{2}}{2 j \omega c e^{j \alpha}} I_{1}
$$

After calculating the Impedance, $\hat{\Gamma}_{\alpha}$ will be deducted, $\alpha$ is replaced by its value $\alpha=\frac{2 \pi \mathrm{p}}{\mathrm{N}}$.

It has the spectral value $\hat{\Gamma}$ :

$$
\hat{\Gamma}=\frac{Z_{\alpha}-Z_{0}}{Z_{\alpha}+Z_{0}}
$$

With:

$$
Z_{\alpha}=-2 j 1 \omega+\frac{\left(e^{j \alpha}-1\right)^{2}}{2 j \omega c e^{j \alpha}}
$$

To find $\mathrm{S}$ in Space domain, Returning to the original scheme to calculate the parameters of the $\mathrm{S}$ matrix in the sources.

The transmission line (Fig. 9) admits as input impedance $Z_{0}$ and a single source at the first cell Ek1, to the remaining cells.

This structure allows writing Equation (15):

$\mathrm{E}=\left(\begin{array}{c}\mathrm{E}_{\mathrm{k} 1} \\ 0 \\ 0 \\ 0 \\ 0 \\ 0\end{array}\right)+\left(\begin{array}{c}-\mathrm{Z}_{0} \mathrm{I}_{\mathrm{N} / 2} \\ 0 \\ 0 \\ 0 \\ 0 \\ 0\end{array}\right)$

Using the two equations governing the iterative method and replacing $E$ in each writing: 


$$
\left\{\begin{array}{l}
A=\frac{1}{2 \sqrt{Z_{0}}}\left(E+Z_{0} J\right) \\
B=\frac{1}{2 \sqrt{Z_{0}}}\left(E-Z_{0} J\right)
\end{array}\right.
$$

In terms of waves the writing becomes Equation (16):

$$
\mathrm{B}=\left(\begin{array}{c}
\mathrm{E}_{\mathrm{k} 1} / 2 \sqrt{\mathrm{Z}_{0}} \\
0 \\
0 \\
0 \\
0 \\
0
\end{array}\right)+\left(\begin{array}{cccccc}
0 & 0 & 0 & 0 & 0 & 0 \\
0 & -1 & 0 & 0 & 0 & 0 \\
0 & 0 & -1 & 0 & 0 & 0 \\
0 & 0 & 0 & -1 & 0 & 0 \\
0 & 0 & 0 & 0 & -1 & 0 \\
0 & 0 & 0 & 0 & 0 & -1
\end{array}\right)\left(\begin{array}{c}
\mathrm{A}_{-\mathrm{N} / 2} \\
\cdot \\
. \\
\cdot \\
. \\
\mathrm{A}_{\mathrm{N} / 2-1}
\end{array}\right)
$$

Representing waves in the spatial domain.

After having calculated $\mathrm{S}$ and $\Gamma$, the current density I on each cell will be determined. To do this, first the capacitance and inductance must be calculated according to the length of the selected cell (Fig. 10).

For a cell with a length of $\delta 1$, capacitance $2 \delta \mathrm{C}$ and a self $2 \delta \mathrm{L}$, this means per unit length:

- $\quad$ Capacitance $\mathrm{C}=2 \delta \mathrm{C} / \delta 1$

- $\quad$ Self $\mathrm{L}=2 \delta \mathrm{L} / \delta 1$

Io our case, the frequency $\mathrm{F}$ equal $3 \mathrm{GHz}$. From the frequency value, the cell longer $\delta 1$ can be calculated by using the equation bellow:

$$
\delta 1=\lambda / 40=0.1 / 40=2.5 \mathrm{~mm}
$$

Thus $\delta \mathrm{L}$ and $\delta \mathrm{C}$ are obtained from the $\mathrm{L}, \mathrm{C}$ and $\delta 1$ values. In first step, $\mathrm{L}$ and $\mathrm{C}$ are derived from the propagation velocity which equal to celerity as explained in the equations bellow:

$$
\sqrt{\frac{\mathrm{L}}{\mathrm{C}}}=50 \text { et } \sqrt{\mathrm{LC}}=\frac{1}{3 * 10^{8}}
$$

Where:

$\mathrm{L}=1.6710-7$

$\mathrm{C}=0.6710-10$

Which amounts:

$\delta \mathrm{L}=1.6710-7 * 1.2510-3$

$\delta \mathrm{L}=2.0910-10 \mathrm{H}$

et

$\delta \mathrm{C}=0.6710-10 * 1.2510-3$

$\delta \mathrm{C}=0.8410-13 \mathrm{~F}$

For a structure of 100 cells and a cell length $\delta 1=$ $\lambda / 40$, we calculated the current density I on each cell.

As can be seen (Fig. 11) the distance between two peaks is about 40 cells $=\lambda$.

For a structure of 100 cells and a cell length $\delta 1=$ $\lambda / 10$, we calculated the current density I on each cell.

As it's clear in figure above, (Fig. 12), the distance between two peaks is about 10 cells $=\lambda$.

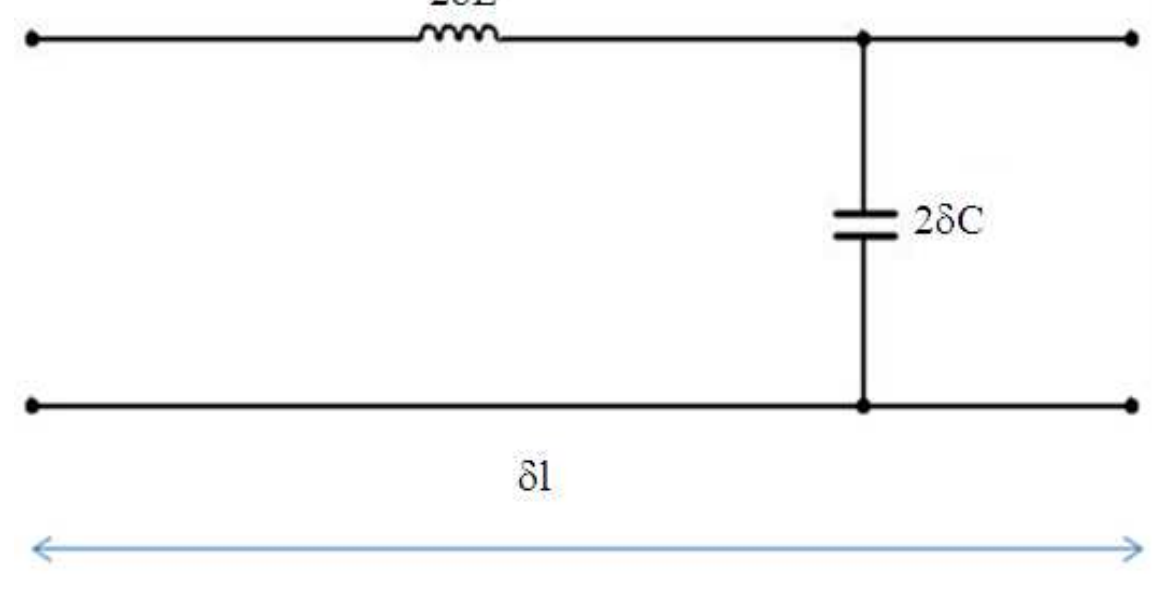

Fig. 10. Cell 


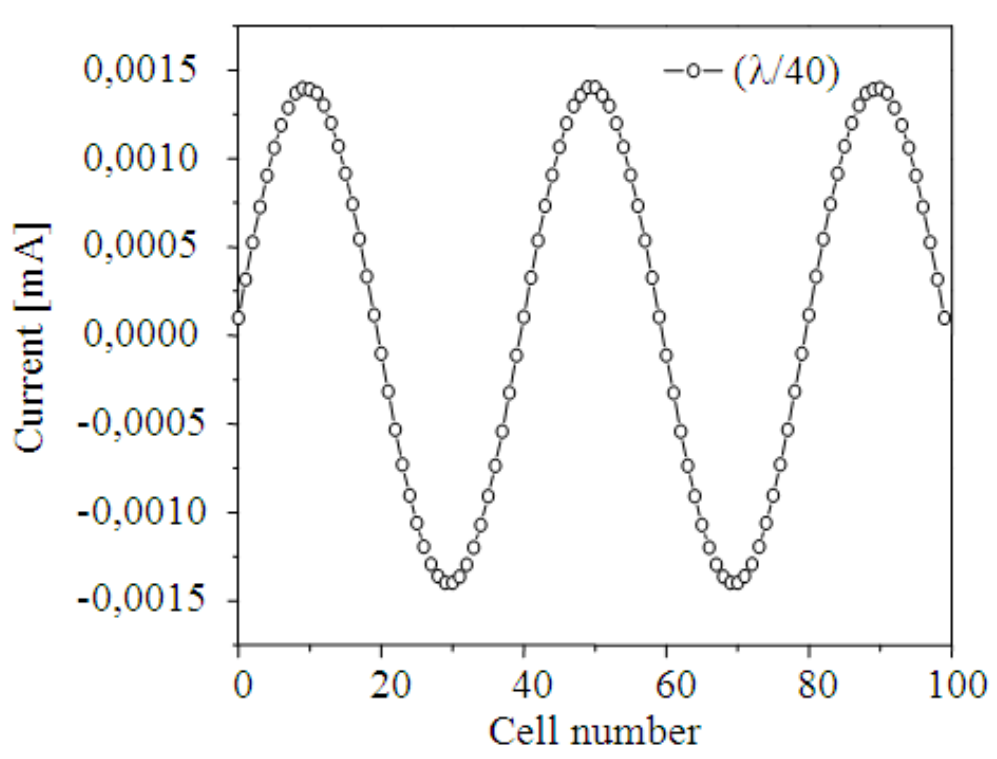

Fig. 11. Current $I=f($ cell number) for $\delta l=\lambda / 40$

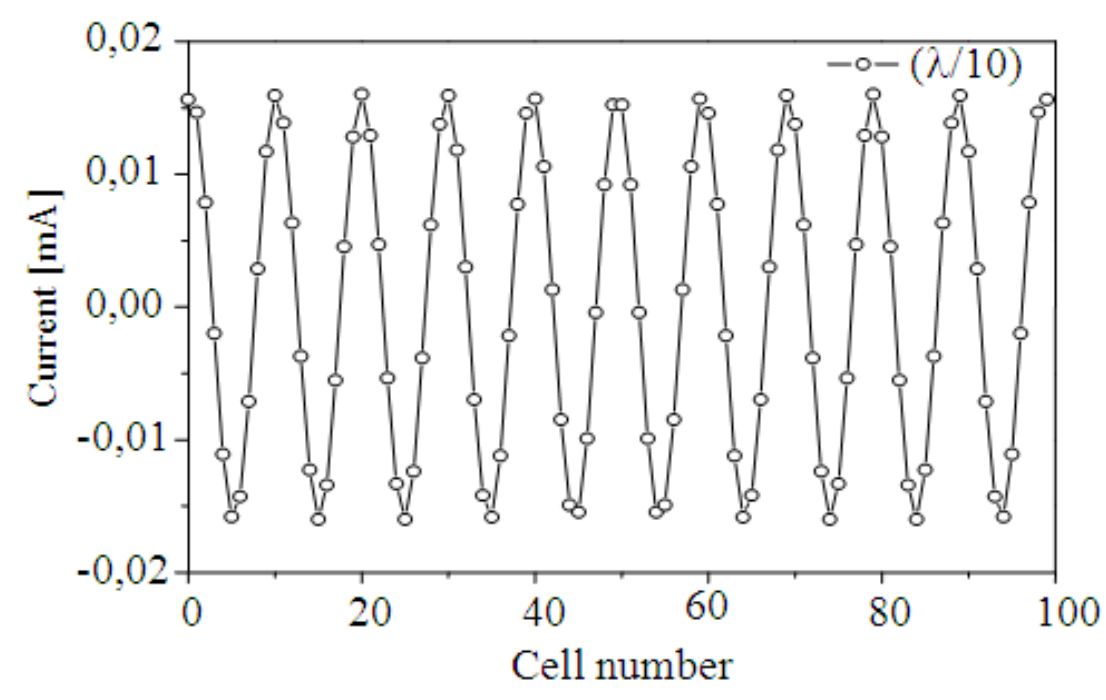

Fig. 12. Current $I=f($ cell number) for $\delta l=\lambda / 10$

\section{ALMOST PERIODIC STRUCTURE BIDIMENSION}

Now almost periodic two-dimensional structures based on what has been done in the previous structure will be treated. It may thus (Fig. 13) the following description.

Due to the periodicity of the structure, one cell study will be good enough to cauterize the proposed design.
From the cell configuration we note that it's composed by three auxiliary sources, Fig. 14.

There is provided the following description of the elementary cell of a transmission line (Fig. 15) with length $\delta 1$ of which is composed of three auxiliary sources E1, E2 and E3 according to the three respective directions $\mathrm{X}, \mathrm{Y}$ and $\mathrm{Z}$ and resistance $\mathrm{r}$, the source $\mathrm{Z}$ is fed and biased $\mathrm{Y}$. 
Mohamed Karim Azizi et al. / American Journal of Applied Sciences 10 (11): 1457-1472, 2013

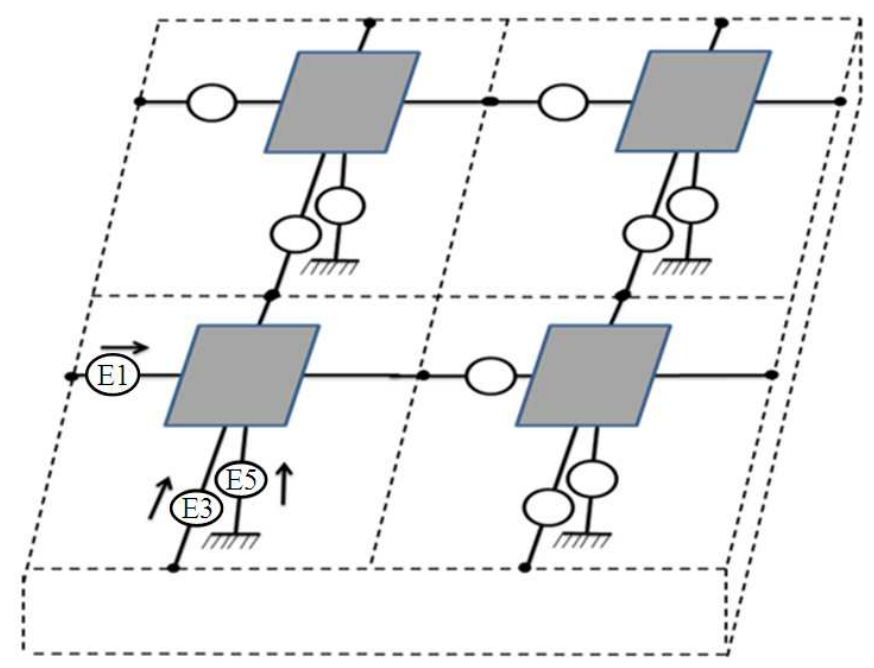

Fig. 13. Almost periodic two-dimensional structure

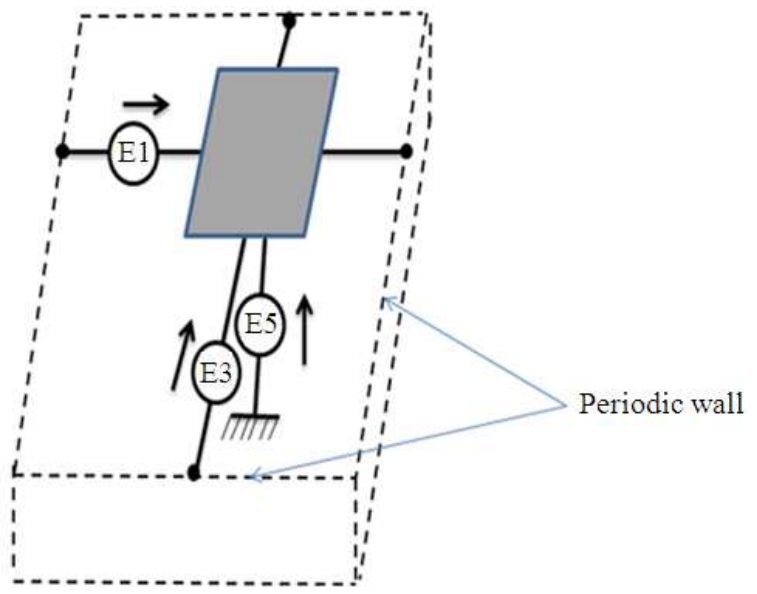

Fig. 14. Representation of a cell by an equivalent circuit showing the auxiliary sources

The sources E1, E2 and E3 are based on electrical walls for having current, otherwise if they rely on walls or periodic magnetic, current power is zero.

There are 8 Equations with 8 unknown Equation (17 to 20$)$ :

$\mathrm{V}_{2}=\mathrm{V}_{4}=\mathrm{E}_{5}$

$\mathrm{I}_{1}+\mathrm{I}_{2}+\mathrm{I}_{3}+\mathrm{I}_{4}+\mathrm{I}_{5}=0$

$\mathrm{V}_{1}+\mathrm{E}_{1}-\mathrm{rI}_{1}-\mathrm{E}_{5}=0$

$\mathrm{V}_{3}+\mathrm{E}_{3}-\mathrm{rI}_{3}-\mathrm{E}_{5}=0$

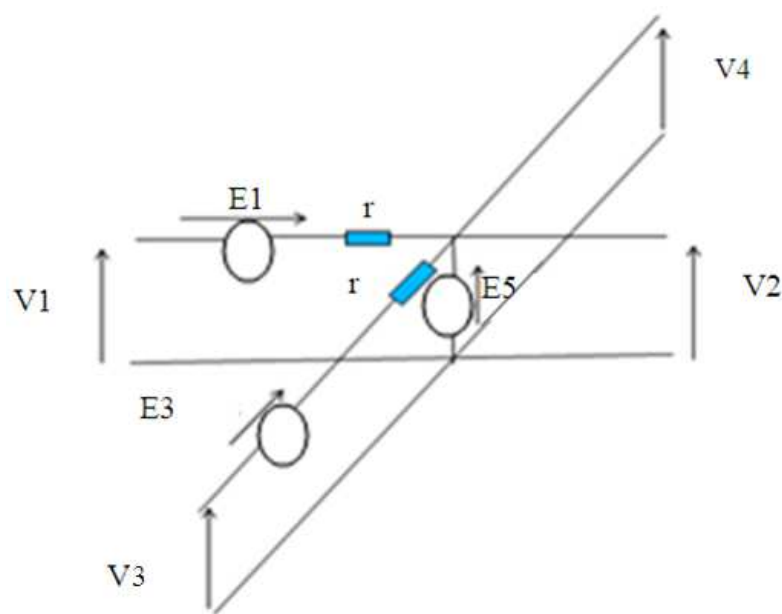

Fig. 15. Elementary cell with 3 sources E1, E3 and E5

The periodicity characterization gives us 4 supplementary Equation (21 to 24):

$\mathrm{V}_{2}=\mathrm{V}_{1} \mathrm{e}^{\mathrm{j} \alpha}$

$\mathrm{I}_{2}=-\mathrm{I}_{1} \mathrm{e}^{\mathrm{j} \alpha}$

$\mathrm{V}_{4}=\mathrm{V}_{3} \mathrm{e}^{\mathrm{j} \beta}$

$I_{4}=-I_{2} e^{j \beta}$

Rewriting these equations by eliminating $\mathrm{V}_{2}, \mathrm{I}_{2}, \mathrm{~V}_{4}, \mathrm{I}_{1}$ Equation (25 and 26): 


$$
\begin{aligned}
& I_{1}\left(1-e^{j \alpha}\right)+I_{3}\left(1-e^{j \beta}\right)+I_{5}=0 V_{1} e^{j \alpha}=V_{3} e^{j \beta}=E_{5} \\
& V_{1}\left(1-e^{j \alpha}\right)+E_{1}-r I_{1}=0 V_{3}\left(1-e^{j \alpha}\right)+E_{3}-r_{3}=0
\end{aligned}
$$

These two equations can be written Equation (27):

$$
\begin{aligned}
& \mathrm{E}_{5} \mathrm{e}^{-\mathrm{j} \alpha}\left(1-\mathrm{e}^{\mathrm{j} \alpha}\right)+\mathrm{E}_{1}=\mathrm{rI}_{1} \mathrm{E}_{5} \mathrm{e}^{-\mathrm{j} \beta}\left(1-\mathrm{e}^{\mathrm{j} \beta}\right) \\
& +\mathrm{E}_{3}=\mathrm{rI}_{3}-\mathrm{rI}_{1}\left(1-\mathrm{e}^{\mathrm{j} \alpha}\right)-\mathrm{rI}_{3}\left(1-\mathrm{e}^{\mathrm{j} \beta}\right)=\mathrm{rI}_{5}
\end{aligned}
$$

With

$$
a=e^{-j \alpha}\left(1-e^{j \alpha}\right) b=e^{-j \beta}\left(1-e^{j \beta}\right)
$$

This will provide Equation (28):

$$
\mathrm{r}\left|\begin{array}{c}
\mathrm{I}_{1} \\
\mathrm{I}_{3} \\
\mathrm{I}_{5}
\end{array}\right|=\left|\begin{array}{ccc}
1 & 0 & \mathrm{a} \\
0 & 1 & \mathrm{~b} \\
\mathrm{a}^{*} & \mathrm{~b}^{*} & |\mathrm{a}|^{2}+|\mathrm{b}|^{2}
\end{array}\right|\left|\begin{array}{c}
\mathrm{E}_{1} \\
\mathrm{E}_{3} \\
\mathrm{E}_{5}
\end{array}\right|
$$

The admittance matrix is written as Equation (29):

$\stackrel{\overline{\mathrm{Y}}}{=} \frac{1}{\mathrm{r}}\left(\mathrm{XX}^{+}+\left(1+|\mathrm{a}|^{2}+|\mathrm{b}|^{2}\right) \mathrm{ZZ}^{+}\right)$

and from there we can deduce Equation (30):

$$
\hat{\Gamma}=\frac{1-Z_{0} \stackrel{=}{\mathrm{Y}}}{1+Z_{0} \stackrel{\bar{Y}}{=}}
$$

With: $\mathrm{Z}_{0}$ reference impedance for the matrix $\mathrm{S}$ :

$$
\mathrm{S}=\left\{\begin{array}{l}
-1 \text { ourt circuit } \\
1 \text { circuit } \text { ouvert }
\end{array}\right.
$$

Once the parameters $\Gamma$ and $\mathrm{S}$ are determined, the iterative process will be very useful in the $\mathrm{E}$ field calculation in the structure.

In order to validate the proposed theory, we use a structure with 64 cells $* 32$ cells where each cell has a dimension about $\lambda / 20$. As explained in previous, only one of the three excitation of the unit cell is activated which is in $Z$ axis, the two other excitation are simply replaced by a self $\mathrm{L}$. By introducing many obstacles cell in the $15^{\text {th }}$ line in this structure, Ez field behavior through the gap between these barriers can be studied (Fig. 16).

Here from the behavior of the density field Ez on each cell, we note that at the $15^{\text {th }}$ line of the level of barriers nothing happens but at the slit we see the passage of the fields Ez and this represents a standing wave. In the next curve, we have a behavior of the field $\mathrm{Ez}$ at the 15th line: 0 to 5 metal, then an opening of 5 to 15 and then 15 to 32 metal.

After studying the Ez behavior field (Fig. 17) throughout the structure by introducing resistors of $5 \Omega$ in each cell, we have tried to tend $r$ to the 0 . One important thing that can be noted is that that the reflection coefficient is now:

$$
\Gamma=1-2 Y^{+}-2 Z Z^{+}
$$

This allows viewing another field Ez behavior throughout the structure (Fig. 18) which gives rise to standing waves behind the obstacle.

The behavior of the field Ez (Fig. 19) is different to that found with the structure of IRIS, we note at the 15 th line there's reflection of Ez fields to the front line, but at the slit waves throughout the rest of the structure can be observed.

As can be seen, the behavior of the fields (Fig. 20) and at the 15th line: 0 to 5 apertures, then metal 5 to 15 and then 15 to 32 apertures.

Letting $r$ to 0 (Fig. 21), A wave reflection at the barrier to the front line and behind the obstacle waves become stationary is noted.

\subsection{Application for a Central Source}

Now, let observe the case where there is a central unit powered by a source $Z$ (Fig. 22), the sources $X$ and $Y$ are replaced by selfs and we search the behavior of Ez field on a structure of $64 * 64$ cells for cell length of the order of $\lambda / 10$.

Activating only the source of the central cell Z (Fig. 23), it is symmetrical about the spread of the x-direction EZ (red curve) and the other on the symmetry of propagation along y EZ (blue curve).

For a cell length of $\lambda / 10$, we see the behavior of $\mathrm{Ez}$ field throughout the structure (Fig. 24), we note that between two maxima of the wave is the distance of the order of 10 cells which verifies our study since the wavelength is of the order of this length.

When we use a structure of $64 *$ cells 64 cells, we can see the behavior of Ez field (Fig. 25) that spreads around the central cell.

To validate this result, we compared the field Ez with Hankel function (Fig. 26) which is used in applications for electromagnetic cylindrical guide, for example, in a problem of diffraction by an infinitely long cylinder and illuminated by a plane wave.

Hankel function tends to 0 while moving away from the center. 
Mohamed Karim Azizi et al. / American Journal of Applied Sciences 10 (11): 1457-1472, 2013

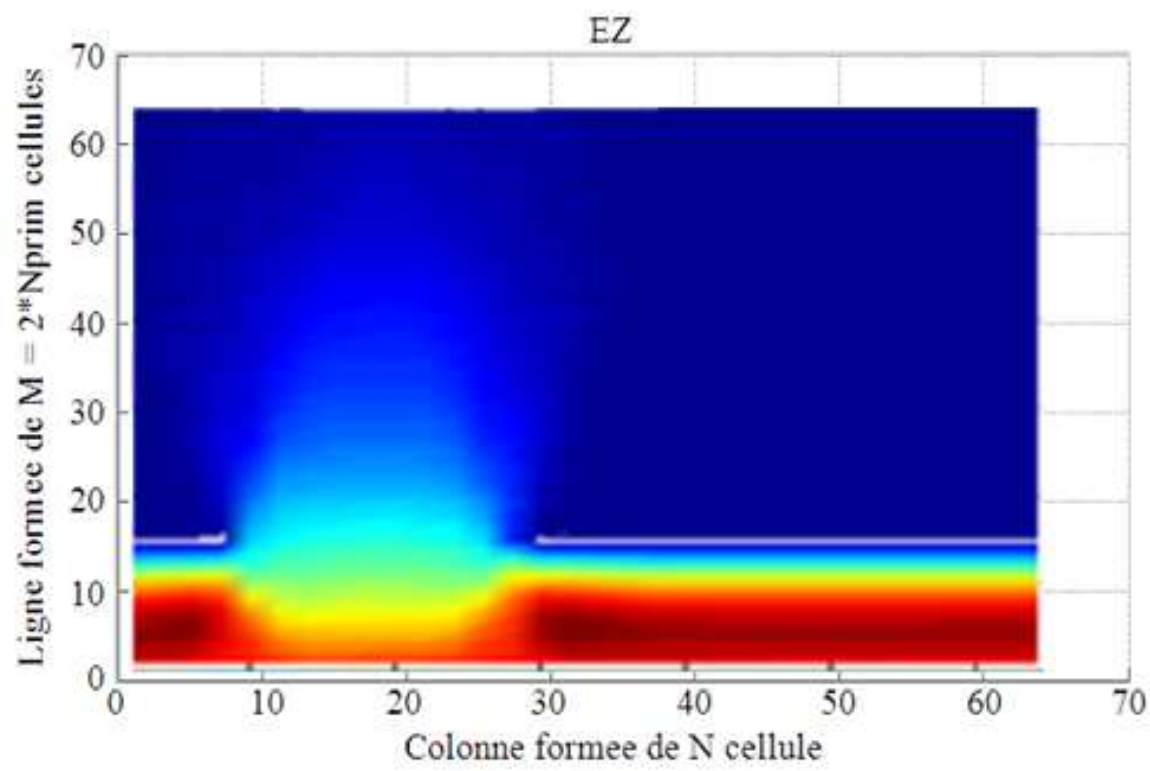

Fig. 16. $E z=f($ cell number $)$ using $r=5 \Omega$

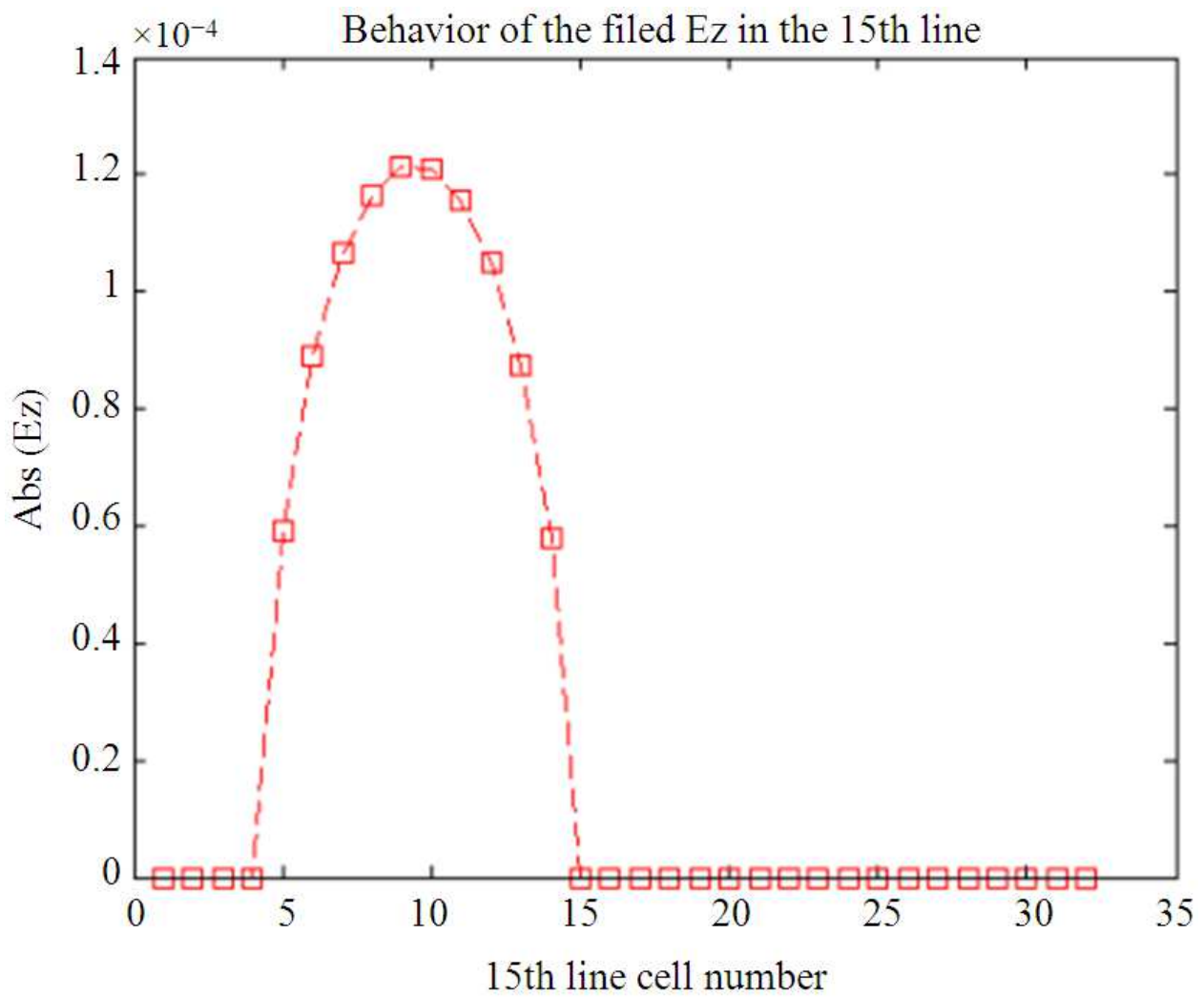

Fig. 17. Behavior of the field Ez in the 15th line 
Mohamed Karim Azizi et al. / American Journal of Applied Sciences 10 (11): 1457-1472, 2013

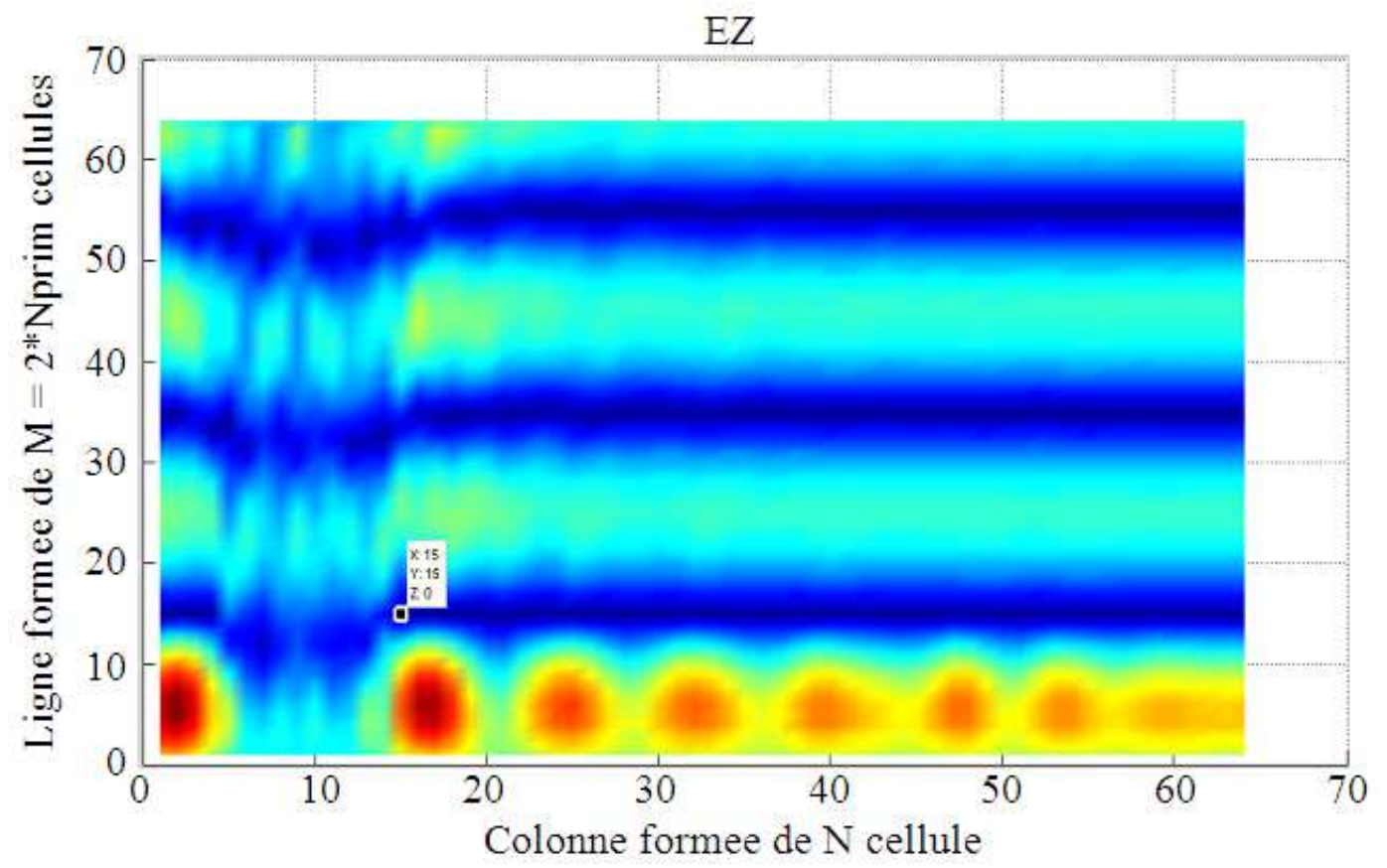

Fig. 18. Field $E z=f($ cell number $)$

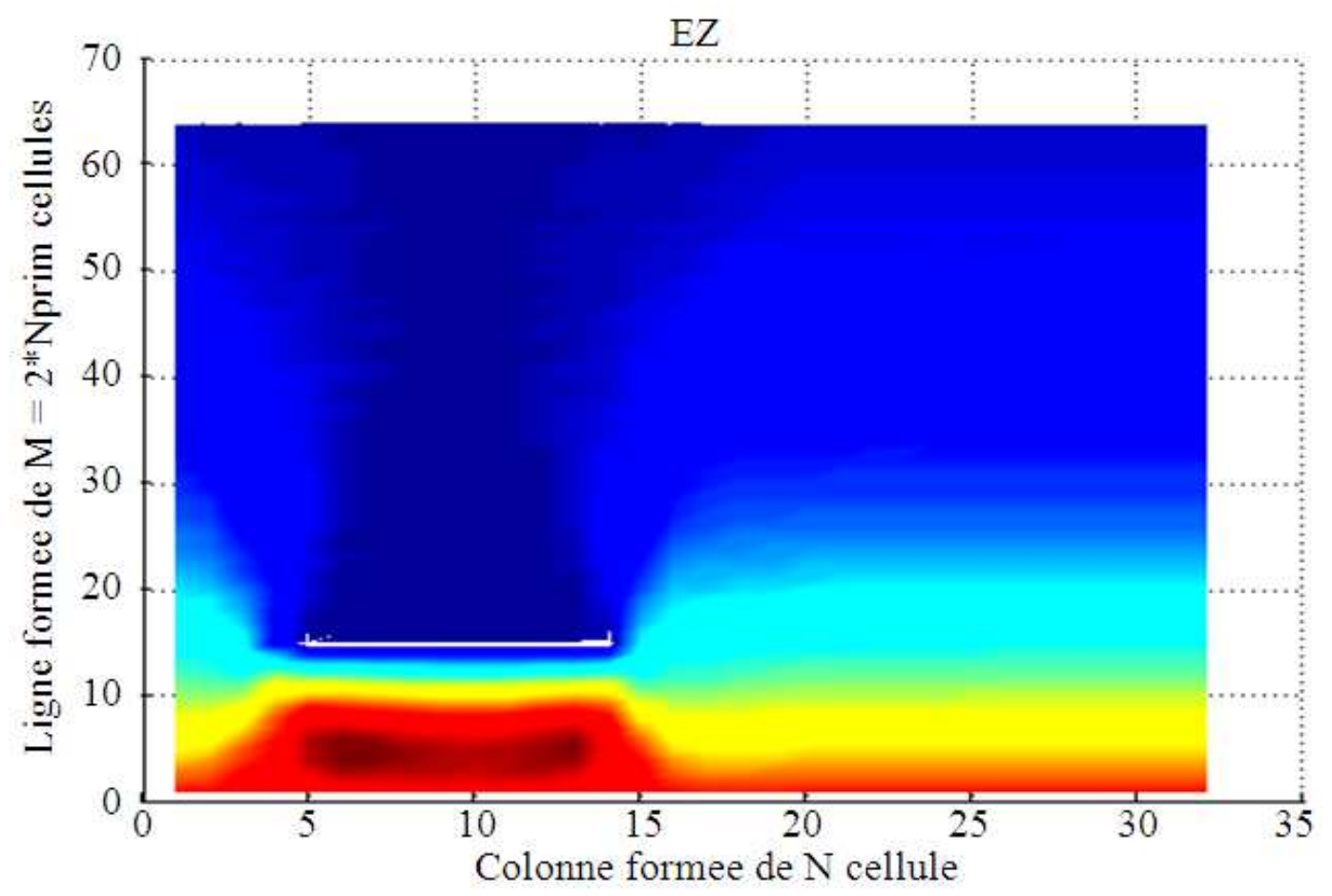

Fig. 19. $\mathrm{Ez}=\mathrm{f}($ cell number $)$ using $r=5 \Omega$ 
Mohamed Karim Azizi et al. / American Journal of Applied Sciences 10 (11): 1457-1472, 2013

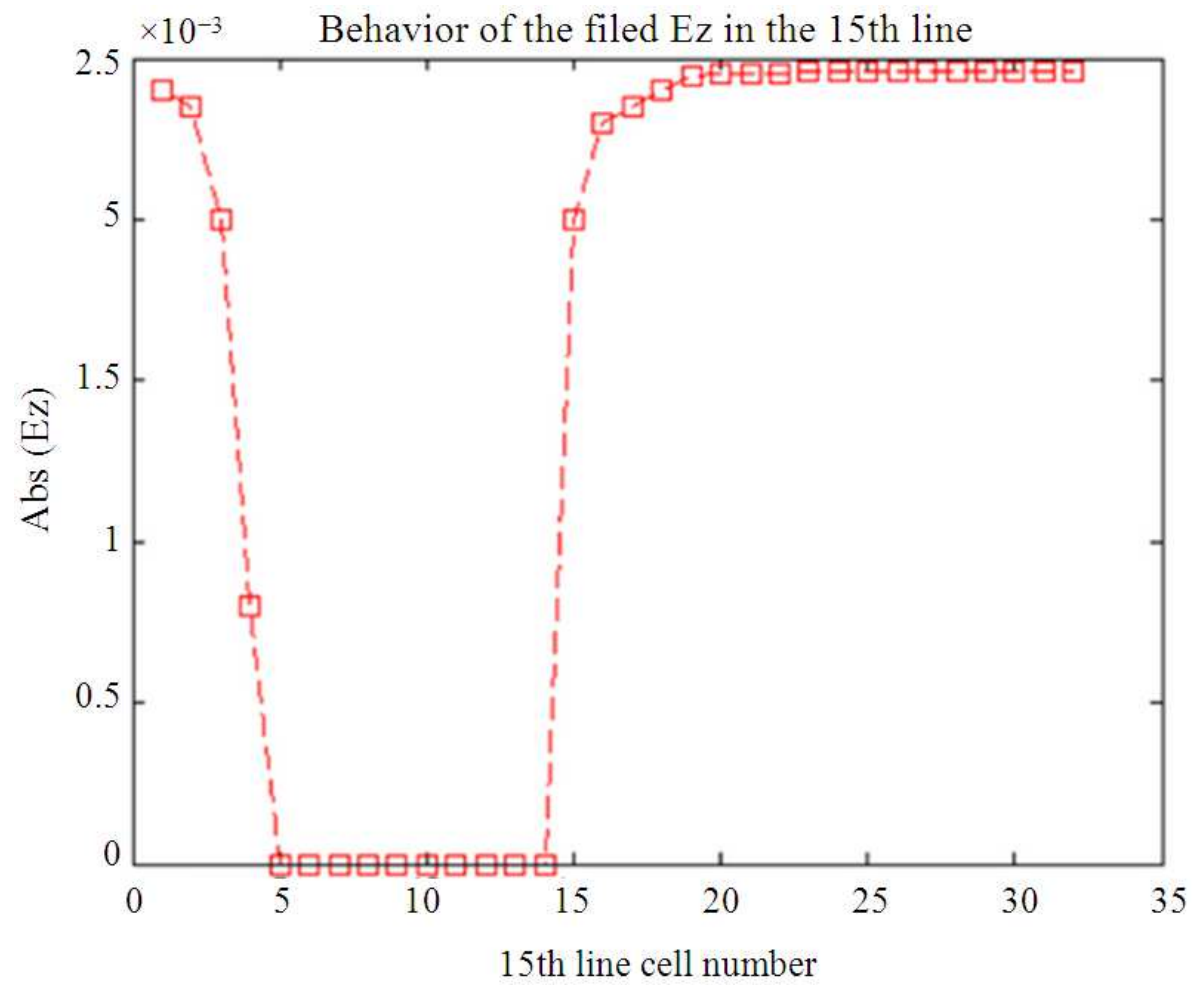

Fig. 20. Behavior of the field Ez in the 15th line

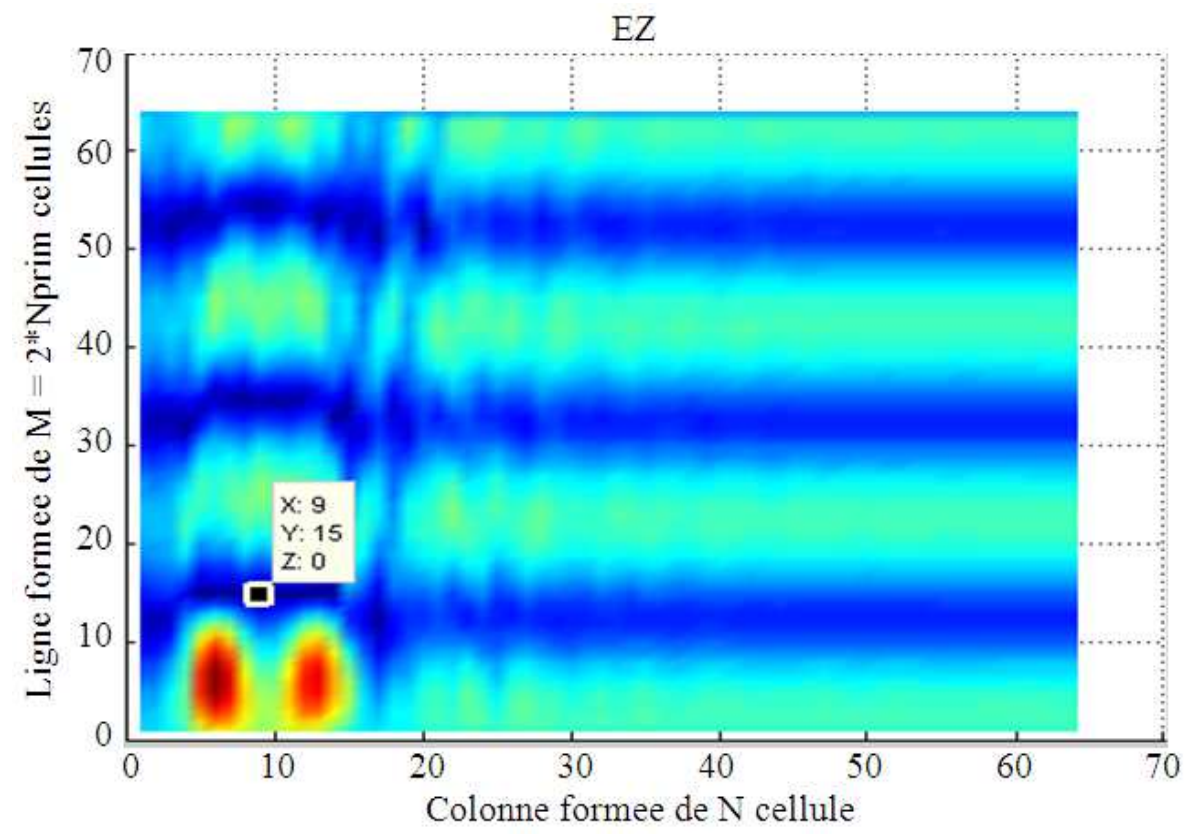

Fig. 21. $E z=$ f cell number) 
Mohamed Karim Azizi et al. / American Journal of Applied Sciences 10 (11): 1457-1472, 2013

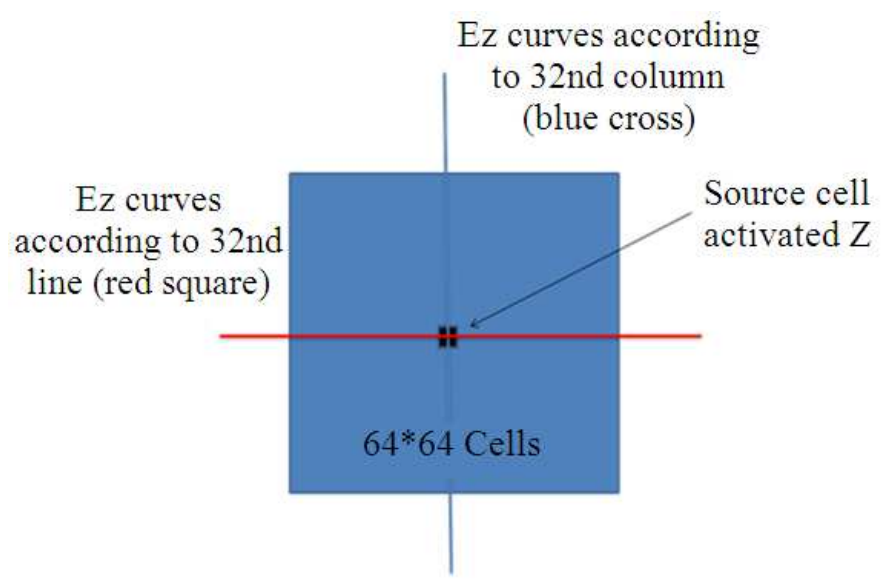

Fig. 22. Description of the structure * 64 cells 64 cells

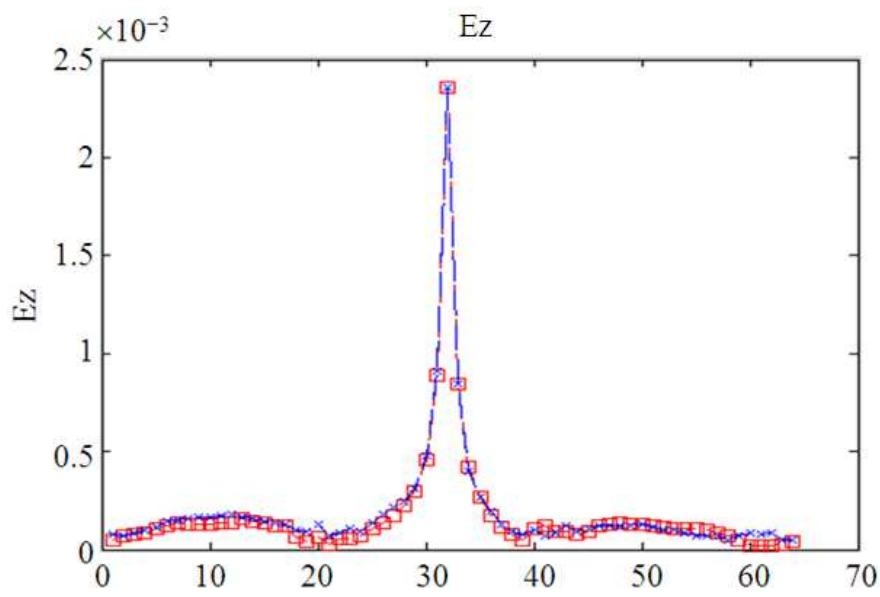

Fig. 23. Behavior of the field Ez at the central source in the $\mathrm{X}$ and $\mathrm{Y}$

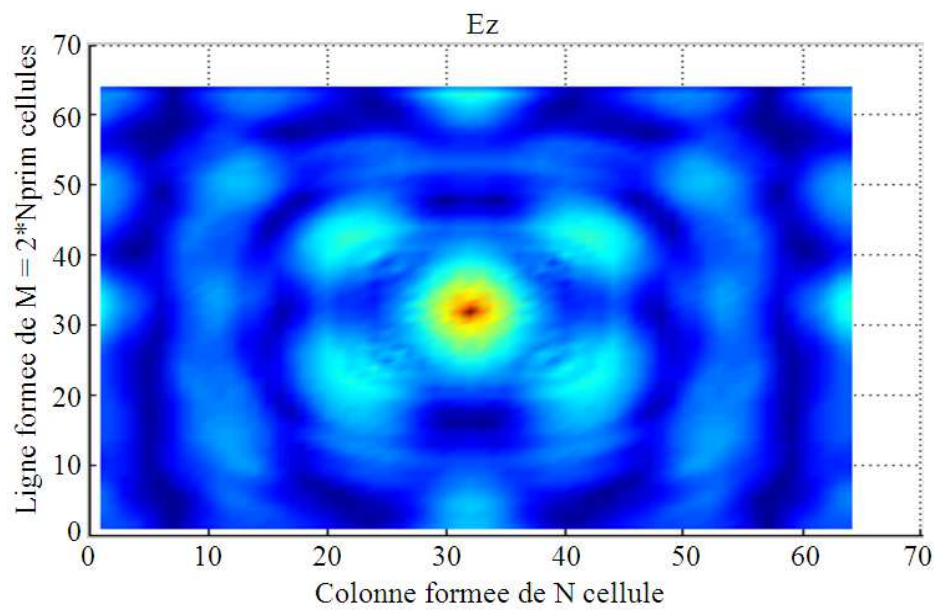

Fig. 24. Field $\mathrm{Ez}=\mathrm{f}($ cell number $)$ for $\mathrm{dl}=\lambda / 10$ 


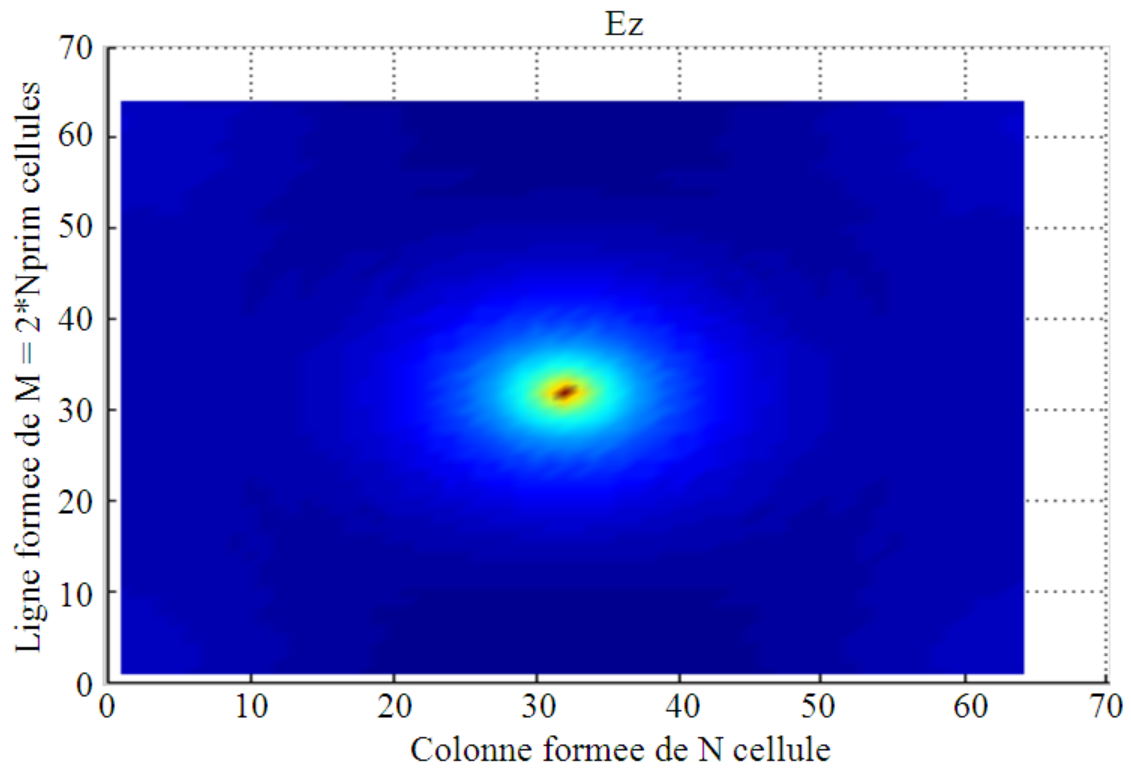

Fig. 25. Field $\mathrm{Ez}=\mathrm{f}($ cell number $)$ for $\mathrm{dl}=\lambda / 100$

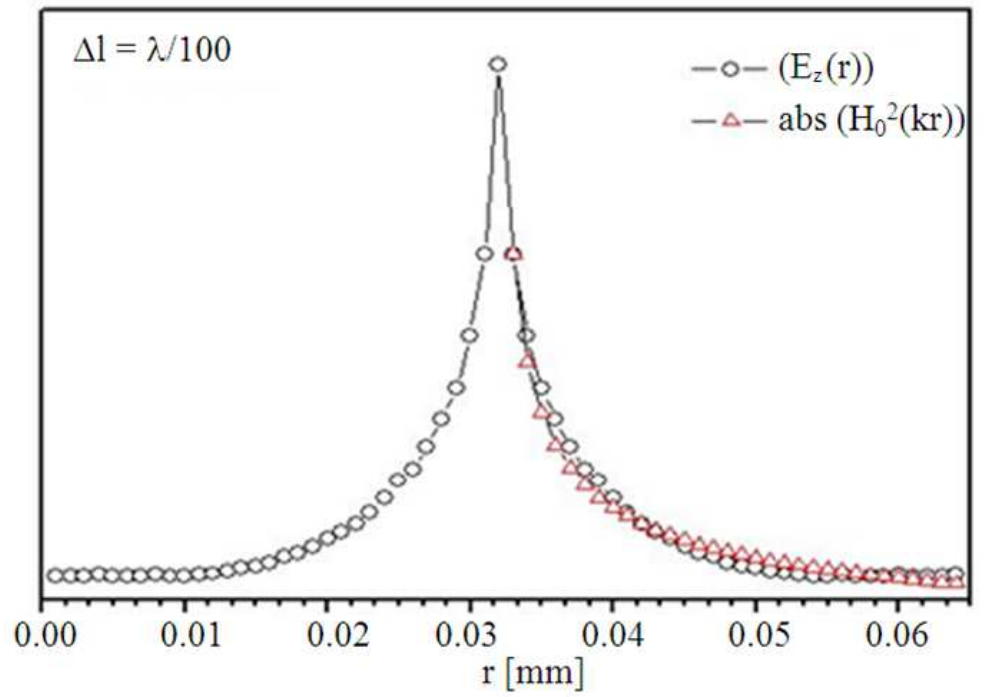

Fig. 26. Comparison of Behavior of the field Ez at the central source in the $\mathrm{X}$ and $\mathrm{Y}$ with Hankel $\mathrm{H}_{0}^{2}(\mathrm{kr})$

\section{CONCLUSION}

The iterative method based on the Wave Concept (WCIP) has shown its effectiveness in the study of almost periodic structures since it can handle a large number of cells through the study of a single unit cell. This allowed us to see the behavior of the field and the current. The advantage of this study is that it does not appeal to the assumptions of each cell coupling because the study of the coupling is done on a single model of the cell.

This study has seen the effectiveness and timeliness of the iterative method using the equivalent diagrams for the study of almost periodic structures. All this study is going to open the door to many areas of research such as métmaterials and the inhomogeneity. 


\section{REFERENCES}

Aroussi, S., L. Latrach, N. Sboui, A. Gharsallah and A. Gharbi et al., 2011. Efficient analysis of complex FSS structure using the WCIP method. J. Electromagnet. Anal. Appli., 3: 447-451. DOI: 10.4236/jemaa.2011.311071

Azizi, M.K., L. Latrach, N. Sboui, A. Gharsallah and H. Baudrand, 2011. Study and conception of dielectric prohibited band-gap structures by the FWCIP method, J. Commun. Comput., 8: 756-762.

Azizi, M.K., N. Sboui, F. Choubani and A. Gharsallah, 2008. A novel design of photonic band gap by F.W.C.I.P method. Proceedings of the 2nd International Conference on Signals, Circuits and Systems, Nov. 7-8, IEEE Xplore Press, Monastir, pp: 1-4. DOI: $10.1109 /$ ICSCS.2008.4746905

Baudrand, H. and R.S. N'gongo, 1999. Applications of wave concept iterative procedure. Recent Res. Devel. Microwave Theory Tech., 1: 187-197.

Baudrand, H. and S. Wane, 2009. Multiscale Circuits: Use of Auxiliary Sources. In: Passive RF Integrated Circuits: Modelling: Characterisation Measurement, Saguet, P. (Ed.), Wiley, ISBN-10: 1848211759, pp: 67-108.

Baudrand, H., M. Titaouine, N. Raveu and G. Fontgland, 2009. Electromagnetic modeling of planar almost periodic structures. Proceedings of the SBMO/IEEE MTT-S International Microwave and Optoelectronics Conference, Nov. 3-6, IEEE Xplore Press, Belem, pp: 427-431. DOI: 10.1109/IMOC.2009.5427552

Eleftheriades, G.V. and K.G. Balmain, 2005. NegativeRefraction Metamaterials: Fundamental Principles and Applications. 1st Edn., John Wiley and Sons Inc., ISBN-10: 0471744743, pp: 316.
Harizi, H. and A. Gharsallah, 2012. Design of pass band filter in hybrid architecture planar/non-radiative dielectric waveguide integration technology. Am. J. Applied Sci., 9: 1538-1541. DOI: 10.3844/ajassp.2012.1538.1541

Houaneb, Z., H. Zairi, A. Gharsallah and H. Baudrand, 2011. Modeling of cylindrical resonators by wave concept iterative process in cylindrical coordinates. Int. J. Numer. Modell., 24: 123-131 DOI: 10.1002/jnm.765

Latrach, L., N. Sboui, A. Gharsallah, A. Gharbi and H. Baudrand, 2009. A design and modelling of microwave active screen using a combination of the rectangular and periodic waveguides modes. J. Electromagnet. Waves Applic., 23: 1639-1648. DOI: 10.1163/156939309789476428

Latrach, L., N. Sboui, A. Gharsallah, A. Gharbi and H. Baudrand, 2008. Analysis and design of a planar multilayered FSS with arbitrary incidence. Applied Comput. Electromagnet. Soc. J., 23: 149-154.

Li, L., D.H. Werner, J.A. Bossard and T.S. Mayer, 2006. A model-based parameter estimation technique for wide-band interpolation of periodic moment method impedance matrices with application to genetic algorithm optimization of frequency selective surfaces. IEEE. Trans. Antennas Propagat., 54: 908-924. DOI: 10.1109/TAP.2006.869915

Wang, Y.Y., Y.J. Xie and H. Feng, 2008. Analysis of cylindrically conformal microstrip structures using an iterative method. Progress Electromagnetics Res., 87: 215-231. DOI: 10.2528/PIER08102402 